by lowering the blood pressure to $70 \mathrm{~mm}$. $\mathrm{Hg}$ for a short period by hypotensive drugs. Alternatively, the sac of the aneurysm can be wrapped around with hammered muscle or with gauze to reinforce its walls. This has to be done carefully and thoroughly, and in my experience has proved satisfactory. It was the sole method employed in 29 of my 108 patients (including three cases with multiple aneurysm), and only one has subsequently bled again (Falconer, 1956b). Hypothermia has been employed by Botterell and his colleagues (1956) as an alternative to hypotension. It still remains to be shown, however, whether the results justify its routine use.

Bleeding arteriovenous malformations have proved readily amenable to surgical treatment, either by direct excision if they are accessible or by ligation or clipping of the main feeding vessels if they are deep-seated. In 1954 I reported operating on 12 consecutive cases without a death. A craniotomy is also indicated whenever the arteriograms indicate a sizable intracerebral haematoma, either in association with an aneurysm or malformation, or occurring without such lesions. The onset of symptoms is usually sudden, but it may be gradual. In the case of an acute and recent haemorrhage it is not wise to operate at once, for most patients with intracerebral haemorrhage will die rapidly whether operated upon or not, and indeed arteriography may aggravate them. Rather should one wait two or three days to see if the coma is lessening before carrying out carotid arteriography and operation to relieve what is in fact a space-occupying lesion. Such haemorrhages will usually be found in the more superficial parts of the white matter of the hemispheres, such as the frontal, temporal, and parieto-occipital lobes, rather than deep in the internal capsule. I have encountered some 10 cases of spontaneous intracerebral haemorrhage without obvious cause. These have all responded well to evacuation of the clot, although three of the patients have subsequently suffered from epilepsy.

There is thus no doubt that timely surgery can greatly improve the prospects of patients with spontaneous intracranial haemorrhage, particularly if they survive the first few days and are in the younger age groups. The commonest indication for surgery is a bleeding intracranial aneurysm, and a sample of the results that have been achieved is given in Table II. It is hoped that with advances in surgical techniques and further experience such results will be improved.

TABLB II.-Operations on 50 Consecutive Aneurysm Patients Up Till July, 1955 (Falconer, 1956a)

\begin{tabular}{|c|c|c|c|c|c|}
\hline \multirow{2}{*}{ Site and Treatment } & \multicolumn{3}{|c|}{ Operation Results } & \multirow{2}{*}{$\begin{array}{c}\text { Late } \\
\text { Deaths }\end{array}$} & \multirow{2}{*}{ Total } \\
\hline & Good & Poor & Died & & \\
\hline $\begin{array}{ll}\text { Internal carotid } & \text { Direct attack } \\
\text { C Carotid ligation } & \ldots\end{array}$ & $\begin{array}{l}6 \\
6\end{array}$ & $\begin{array}{l}1 \\
2\end{array}$ & $\begin{array}{l}\mathbf{0} \\
\mathbf{0}\end{array}$ & $\begin{array}{l}0 \\
1\end{array}$ & \} 16 \\
\hline Carotid bifurcation $\left\{\begin{array}{l}\text { Direct attack ... } \\
\text { Carotid ligation }\end{array}\right.$ & $\begin{array}{l}1 \\
1\end{array}$ & $\begin{array}{l}\mathbf{0} \\
\mathbf{0}\end{array}$ & $\begin{array}{l}0 \\
1\end{array}$ & $\begin{array}{l}\mathbf{0} \\
\mathbf{0}\end{array}$ & \} \\
\hline $\begin{array}{l}\text { Anterior communicating: Direct attack } \\
\text { Anterior cerebral: Diret attack } \\
\text { Mindle cerebral: Direct attack } \\
\text { Basilar: Vertebral ligation } \quad . . \\
\text {.. }\end{array}$ & $\begin{array}{r}10 \\
1 \\
7 \\
2\end{array}$ & $\begin{array}{l}\mathbf{0} \\
\mathbf{0} \\
\mathbf{0} \\
\mathbf{0}\end{array}$ & $\begin{array}{l}1 \\
1 \\
0 \\
0\end{array}$ & $\begin{array}{l}1 \\
0 \\
0 \\
1\end{array}$ & $\begin{array}{r}12 \\
2 \\
7 \\
3\end{array}$ \\
\hline \multirow[t]{2}{*}{ Multiple $\left\{\begin{array}{l}\text { Direct attack } \\
\text { Carotid ligation }\end{array}\right.$} & $\mathbf{1}$ & $\begin{array}{l}2 \\
0\end{array}$ & 0 & $\begin{array}{l}\mathbf{0} \\
1\end{array}$ & \} 7 \\
\hline & 38 & 5 & 3 & $4 *$ & 50 \\
\hline
\end{tabular}

- One patient died of coronary thrombosis, the remainder presumably of iecurrent bleeding.

REFERENCES

Beck, D. (1953). Arch. Middx Bosp., 3, 150.

Botterell, B. H., Lougheed. W. M., Scott, J. W., and Vandewater, S. L. (1956). J. Neurosurg. 13. 1.

Falconer, M. A. (1950). Brit. med. J., 1, 809.

Falconer, (1951). J Neurol. Neurosurg. Psychiat., 14, 153.

- (1952). Lancet. 2. 945.

- (1954). Proc. roy. Soc. Med.. 47, 693.

- (1956a). Ibid., 49. 106

- (1956b). Brtt. med. J., 1, 743.

- (1956c). Ibid , 1, 1172

Gillingham, F. J. (1957). Huntcrian Lecture, Royal College of Surgeons of England.

Hamby, W. B. (1948). J. Amer. med. Ass., 136. 522.

Hyland, H. H. (1950). Arch. Neurol. Psychiat. (Chicaso), 63, 61.
Logue, V. (1956). Brit. med. J., 1, 473.

McKissock, W. and Walsh, L. (1956). Ibid., 2, 559.

Magee, C. G. (1943). Lancet. 2. 497.

Mount, L. A. (1951). J Amer. med. Ass., 146. 693.

Norlén. G., and Olivecrona, H. (1953). J. Neurosurs., 10, 404.

Richardson. J. C., and Hyland, H. H. (1941). Medicine (Baltimore), 20. 1 Small, J. M., Holmes, J. M., and Connolly, R. C. (1953). Brit. med. J., 2. 1072 .

Walton. J. N. (1952) Ibid., 2, 802.

- (1956). Subarachnold Haemorrhage. Livingstone, Edinburgh

Wilson, S. A. Kinnear (1940). Neurology, vol. 2. Arnold, London.

=

\section{THE MANAGEMENT OF STROKES*}

BY

\author{
F. A. ELLIOTT, M.B., F.R.C.P. \\ Neurologist, Charing Cross Hospital, London
}

The rising tide of coronary disease in recent years has attracted more attention than the simultaneous increase in the incidence of cerebrovascular disease. The survey by Riishede (1956) shows that since 1943 there has been a steady rise in deaths from strokes in the U.S.A., the British Isles, and most of Western Europe, and it is safe to predict that if figures were available they would show an even larger increase in the morbidity from non-fatal strokes, because chemotherapy saves so many victims who would formerly have died from post-ictal bronchopneumonia. The medical, social, and economic problems which arise from this situation are likely to grow progressively worse in our ageing populations until means are found of preventing or retarding the development of atherosclerosis and its complications. In the meantime, however, we have to treat these conditions as best we can.

Therapeutic possibilities are sharply limited by the circumstance that in many cases the damage is already done by the time the doctor sees the patient. Nevertheless, there is often the possibility of further deterioration, and treatment should therefore be given to prevent it. But what treatment ? In the first critical hours, when treatment might have some chance of success, it is often impossible to distinguish between haemorrhage, thrombosis, haemorrhagic infarction, embolism, and the much-debated arterial spasm. Thus in a large series of cases reported by Dalsgaard-Nielsen (1956) necropsy revealed an incidence of error of $35 \%$ in cases diagnosed as haemorrhage, and an even higher rate of error in thrombo-embolic cases. Of course, the longer the patient survives the more chance there is of investigation and the lower the rate of mistake. However, this is cold comfort to the doctor who wishes to give appropriate and rational treatment to the patient at the very earliest possible moment.

With regard to the treatment of cerebral haemorrhage, the use of ganglion-block to lower blood pressure is a theoretical possibility, for -we know that the rate of bleeding is much reduced when the systolic blood pressure is reduced to the region of $80 \mathrm{~mm}$. of mercury and that this reduction does not significantly impair the rate of blood flow in the main cerebral and coronary arteries. Unfortúnately this is not as safe as it sounds, for, as Bessman et al. (1952) have shown, a fall of blood pressure which is ordinarily safe will on occasion bring about a dangerous reduction of the blood flow. This, of course, would probably aggravate the situation in a case of cerebral thrombosis misdiagnosed as haemorrhage. So, for the present, hypotensive therapy is not to be recommended, though advances in techniques,

*Read to the Section of Neurology at the Annual Meeting of the British Medical Association, Newcastle upon Tyne, 1957. 
both diagnostic and pharmacological, may eventually make it a practicable proposition-that is, something that can be carried out in the home or in the casualty department at the earliest possible moment in the evolution of the haemorrhage.

In thrombosis and embolism, on the other hand, the scene is not quite so dark. The main interest centres in two questions: the role of arterial spasm and the use of anticoagulants.

\section{Focal Arterial "Spasm"}

The idea of focal arterial spasm was introduced by Peabody in 1891 to explain brief cerebral episodes, abrupt in onset and brief in duration, which occur in hypertensive and arteriosclerotic persons, and the concept appeared to derive additional support from the fact that areas of cerebral softening are sometimes found without occlusion of the artery concerned. However, it is now known that these softenings can be caused by atheromatous stenosis of the extracranial portion of the carotid and vertebral arteries and also by emboli from the heart and from atheromatous plaques on the great vessels ; such emboli have sometimes broken up and moved on, leaving a patent artery, before the patient has died and come to necropsy. It is interesting to recall that, when in 1911 Osler gave his rather reluctant but much-quoted support to Peabody's idea, it was through his experience with the very type of case which we now know to be suffering from stenosis of the carotid artery. Nevertheless, the fact that Peabody's hypothesis was too widely applied does not mean that it is wholly untrue.

It is known that cerebral arteries can go into spasm both in animals and in man as a result of needling, manipulation, and the impaction of emboli. They do not always do so, but they can. It is suggested by some, and denied by others, that embolism, subintimal haemorrhage, and thrombotic occlusion will occasionally cause local arterial spasm in the affected vessel and its collateral branches, and that this spasm is responsible for at least some of the patient's incapacity. The main argument in favour of this is the abrupt and almost instantaneous improvement which sometimes follows measures designed to promote vasodilatation. Such recovery occurs in a minority of the cases treated and is often unsustained, but nobody who has witnessed this phenomenon can doubt that the dramatic change in the patient's condition, occurring within a minute or two of treatment, is in fact due to that treatment, though it is of course possible that some as yet unidentified mechanism, other than the relief of spasm, is involved.

Of the measures adopted for the relief of this hypothetical spasm, stellate block has been given a thorough trial since Leriche and Fontaine (1936) published their first experience thereof. Although some authors have had favourable results (Risteen and Volpitto, 1946; Naffziger and Adams, 1950 ; Searles et al., 1950; Walsh, 1956) many authorities regard the results as inconclusive and inadequately controlled, and it is not yet possible to make a final assessment of this matter. There are the additional theoretical objections that neurocirculatory control in the brain is exceedingly weak, and that bilateral stellate block does not increase the cerebral blood flow (Harmel et al., 1949).

Intravenous papaverine, in doses of $100-200 \mathrm{mg}$. in $100 \mathrm{ml}$. of saline over a period of 10 minutes, is, on the other hand, a very powerful cercbral vasodilator, as can be shown by cerebral blood-flow tests. by spinal monometry, and by angiography (Shenkin, 1951; Rich et al., 1953; Morello et al., 1956). It is easy to administer and apparently harmless, but-and this is an important point-Rich and his colleagues found that it did not have a consistent vasodilator effect in his middle-aged subjects. Nevertheless it would certainly seem to deserve a more extended trial as an immediate and early treatment for thrombosis and embolism.

Tolazoline hydrochloride ("priscol") is variable in its effects. I have found that an intravenous dose of $50 \mathrm{mg}$. in- jected over one minute can cause an immediate sharp rise in cerebrospinal fluid pressure accompanied by a fall in the mean arterial blood pressure, lasting only thred or four minutes. As in the case of papaverine, it does not always work. Engel (1950) has found that tolazoline dilates the pial vessels in the cat. On the other hand, cerebral blood-fiow tests suggest that tolazoline does not dilate cerebral vessels (Scheinberg et al., 1953 ; Clarke et al., 1954), but it is unlikely that the very brief vasodilatation indicated by the rise of cerebrospinal fluid pressure would influence cerebral blood-flow tests as carried out by the nitrous oxide method.

There have been many reports of abrupt objective improvement after the intravenous administration of tolazoline to people suffering from thrombo-embolic disease. There seems to be no doubt that it sometimes works and that in such cases the speed of recovery exceeds anything that occurs spontaneously in cerebrovascular accidents. For instance, in a case at Charing Cross Hospital, a man of 65 with a left hemiplegia recovered the use of his arm and leg within about a minute of the injection; the improvement lasted several hours, but the following morning he was hemiplegic again, and on this occasion tolazoline failed to produce any improvement. The variable but sometimes severe fall of blood pressure which follows tolazoline is a contraindication to its continuous use by infusion, because of the danger of producing thrombosis or softening as a result of this hypotension. The fall of blood pressure is so brief following a single injection that this is no contraindication to its use in this way. Tolazoline and other vasodilator substances are sometimes given into the carotid artery, but this has nothing to recommend it. It can be difficult and painful and may be positively harmful, since needling of the carotid is one of the best ways of inducing arterial spasm.

The inhalation of $5 \%$ carbon dioxide in oxygen greatly increases cerebral blood flow and-unlike other vasodilators - maintains the level of the blood pressure, but it has not proved useful in relieving the symptoms in acute cerebrovascular accidents (Altschule, 1954). This failure may be due to the narcotic quality of carbon dioxide-which is present in high concentrations in the ischaemic tissues anyway. Intravenous infusion of $900 \mathrm{ml}$. of $3 \%$ sodium bicarbonate solution in one hour promotes cerebral blood flow by reducing cerebrovascular resistance (Schieve and Wilson, 1953 ; Rich et al., 1953), but there is as yet no information as to whether this method is effective in relieving cerebral symptoms ; the volume of fluid used would appear to be a disadvantage.

It would seem, therefore, that at the present time we have to rely on tolazoline and papaverine given by intravenous injection, and given early. Success can be expected in only a minority of cases; that is, those in which vasoconstriction or failure of the collateral circulation is playing a definitive part, and there is no way of identifying these cases in advance. What is needed is a simple method of inducing a more persistent vasodilatation in the brain without a parallel fall of blood pressure. The xanthines, including aminophylline, constrict the cerebrovascular vessels and reduce cerebral blood flow. Alcohol, given in either social or medicinal quantities, is a weak vasodilator, but does not appear to have any effect on the cerebral blood flow.

\section{Anticoagulants}

The value of the so-called anticoagulants in cerebrovascular disease is still undecided. The heparins, which are the only true anticoagulants known, cannot be used for more than a few days, for practical reasons, so we have to rely on the coumarins and the chemically related phenindione (" dindevan "), which do not in fact prevent coagulation but appear to improve the prognosis in cornnary disease and venous thrombosis. There is evidence that they accelerate the canalization of thrombi, while long-term clinical trials have shown that they reduce the incidence of embolism following coronary disease, and in this respect, at any rate, 
improve the prognosis: It has been suggested also that the long-term administration of the coumarins is indicated in cases of suspected or proved carotid and vertebral arterial stenosis. The idea is to prevent thrombosis in the collateral circulation. It will take time to assess the truth of these claims. The coumarins have many disadvantages: they do not always prevent thrombosis, they can cause serious haemorrhage into the brain and elsewhere even if the prothrombin time is within the safe range, and they require constant laboratory control. Moreover, they should not be used at the same time as salicylates or oral antibiotics; nor are they safe in severe anaemia, hepatic cirrhosis, renal failure, infective endocarditis, and conditions in which there is ulceration within the alimentary canal.

It seems possible that in the not-too-distant future the physician may have more to offer the patient suffering from cerebrovascular disease. The revival of Rokitansky's theory of atherosclerosis by Duguid and Robertson (1957) focuses attention on the fact that deposits of fibrin on the arterial wall play a part, perhaps the main one, in the production of thrombotic occlusion. If this is so, it is logical to seek for a method of removing such deposits as they occur. The plasma fibrinolysins normally exert some influence in this direction, and efforts are being made in various quarters to produce a fibrinolytic agent or, alternatively, to find something which will activate the native fibrinolysins in the patient's plasma. Fletcher et al. (1956) have succeeded in producing a purified form of streptokinase which increases the fibrinolytic activity of the plasma in vivo, and we await the result of clinical trials. Fishman and Kling (1956) are developing the use of plasmin derived from human bloodthat is to say, they are trying to isolate and use naturally occurring fibrinolysins.

\section{General Measures}

Finally, I must deal very briefly with the general measures applicable to all strokes, measures which can both save life and reduce subsequent incapacity. In the acute phase the head and shoulders should be raised, to reduce intracranial venous pressure, because a high venous pressure aggravates both haemorrhage and the effects of ischaemia. The pharynx is kept clear of secretions by swabbing or by suction. Long-acting penicillin will reduce liability to infection. The bladder must be emptied, whether by carbachol or by catheter, not less than twice daily, because retention of urine for as little as 12 hours can start an intractable cystitis. Opinion is divided regarding the usefulness of repeated magnesium sulphate enemata for the reduction of cerebral oedema following thrombo-embolism. I am not convinced that they do any good at all. The pressure points, and passive movements of paralysed limbs, should receive attention thrice daily from the very start of the illness, and it is better for these things to be done by an unskilled attendant than for them not to be done at all. Headache responds better to heroin than to anything else; morphine is, of course, contraindicated in all acute cerebral catastrophes. Paraldehyde by intramuscular injection is useful for controlling restlessness. Fluid intake is not important in the first 24 hours, except in tropical conditions. If the patient cannot swallow, a nasal tube is indicated, and through it he can receive both fluid and soluble carbohydrate, with a gradual return to conventional invalid fare. But I would make a plea for a restriction of all fats of animal origin, including butter and unskimmed milk, both in the acute stage and thereafter, for there is some evidence that such fats, or something connected with them, can have a malign effect in vascular disease. Lipaemia of moderate degree increases blood viscosity and induces sludging (Cullen and Swank, 1954), and it inhibits the activity of many enzymes (Bornstein, 1956), especially the plasma fibrinolysins which are concerned with the removal of thrombi (Greig, 1956); it probably increases the coagulability of the blood as well, though this is disputed (Fullerton et al., 1953 ; Hall, 1956). Fats of vegetable origin appear to be less harmful in these respects.

\section{Conclusion}

Although the methods I have outlined may sometimes save life and either prevent or limit subsequent disability, there can be no blinking the fact that their main effect is to prolong the life of disabled persons. Therefore it is clear that what is really needed is a method of anticipating and preventing these disasters. Some of them would be avoided if, by annual medical examination of the population at risk, men and women suffering from early arteriosclerosis and hypertension could be identified and given sensible advice about the management of their lives and the use of such prophylactic measures as are available at the present time. If annual interviews are carried out in the right way they do far more to remove hypochondriasis than to foster it.

Secondly, we need improved anticoagulants, better vasodilators, and more reliable hypotensive drugs, and we must explore the possibilities of fibrinolysins, dietetic control, and the surgical treatment of stenosis in major arteries to the brain. The problems involved are those of vascular disease in general-and it is as well to remember that vascular disease of the brain and heart together kill more than two and a half times as many people as all forms of cancer. The urgency of the situation may be judged from the fact that in England and Wales deaths from strokes rose by over 14,000 between 1949 and 1955, and there is presumably an even greater increase in the number of incapacitated survivors. Moreover, the rising mortality involves people both under and over the age of 65 .

From the economic standpoint alone it would seem prudent to foster research in this subject and to make generous provision-in time, space, and tools - for those engaged in it. Furthermore, there must be close and continuous co-operation between clinicians and medical scientists, and between different groups working in the same field. These requirements, which are common to all branches of medical research, cannot be met without the active and imaginative assistance of both lay and medical administrators, and it is to be hoped that they too will bring to this problem the vigour which the situation demands.

\section{REFERENCES}

Altschule, M. D. (1954). Transactions American Heart Association, D. 96 Princeton, N.J. intern. Med., 89, 893.

Bornstein. J. (1956). Biochth

S67.

Cullen, C. F., and Swank, R. L. (1954). Circulation, 9, 335

Dalszaard-Nielsen, T. (1956). Acta psychiat. scand.. Supp]. 108, 101

Duguid. J. B.. and Robertson, W. B. (1957). Lancet, 1, 1205.

Engel, D. (1950). Acta Dsychlat. (Kbh.), 25, 153.

Fishman.

Fletcher, A. P., Johnson. A. J., and McCarty, W. R. (1956) J. clin. Invest., 35." J03.

Fullerton. H. W., Davie, W. J. A., and Anastosopoulos, G. (1953). Brit. med. J., 2, 250 .

Greis. H. B. (1956). Lancet, 2, 16

Hall. G. H. (1956). Brt. med. J., 2, 207.

Harmel, M. H.. Hafkensihiel, J. H. Austin, G. M., Crumpton, C. W., and Kety, S. S. (1949). J. clin. Invest., 28, 415 .

Leriche. R., and Fontaine. R. (1936). Rev. Chtr. (Paris). 74. 755. Morello, A., Bartecek, A., Stellar, S., and Cooper, I. S. (1956). Angtology. 7. 16

Naffiziger. H. C., and Adams, J. E. (1950). Arch. Surg. (Chicago), 61, 286 ONler. W. (1911). Canad. med. Ass. J.. I. 919.

Peabody. G. (1891). Trans. Ass. Amer. Phycns, 6. 170

Rich. M.. Scheinberg. P.. and Be'le, M. S. (1953). Circulat. Res., 1, 389. Riishere. J. (1956). Acta psychiat. scand.. Suppl. 108. 347.

steen, W. A., and Volpitto, P. P. (1946). Sth. med. J. (Bgham, Ala.)

Scheinberg, P., Blackburn, I, and Rich. M. (1953). J. clin. Invest., 32, 125. Schieve, F. and Wilson, W P. (1453). Ibid. 32,33 .

Searles P. W., and Nowill. W. K. (1950). Sth. med. J. (Bgham, Ala.), 43. Thentin.

Shenkin, H. A. (1951). J. app. Phystol., 3, 465.

Walsh. R. C. (1956). Proc. roy. Soc. Med., 49. 161. 